\title{
A paisagem de ponta-cabeça
}

Landscape Upside Down

Paisaje al revés

Gilles Tiberghien (Paris I - Panthéon-Sorbonne, França) ${ }^{1 *}$

Tradução: Pedro Hussak (Universidade Federal Rural do Rio de Janeiro, Brasil) ${ }^{* *}$

https://doi.org/10.22409/poiesis.v21i36.42733

RESUMO: Estamos interessados aqui em olhar para a paisagem de uma maneira diferente daquela que nos é usual e à qual muitas vezes nós a reduzimos. Em vez de horizontalmente, através de um quadro e de um ponto de vista, a ideia é considerá-la verticalmente, de cima ou de baixo, mostrando que essas formas de a olhar estão de alguma forma em potência na nossa apreensão de qualquer paisagem. Este texto explora essas potencialidades através da arte e da literatura.

PALAVRAS-CHAVE: horizonte; vista zenital; paisagens subaquáticas; artes visuais e literatura

\footnotetext{
* Gilles A. Tiberghien é Professor de Estética na Université Paris 1 - Panthéon-Sorbonne, França. E-mail: gillestiber@gmail.com. 
ABSTRACT: We are interested here in looking at the landscape in a different way from the usual to us and to which we often reduce it. Rather than horizontally, through a framework and from a point of view, the idea is to consider it vertically, from above or below by showing that these ways of looking at it are in some way in potency in our apprehension of any landscape. This text explores these potentials through art and literature.

KEYWORDS: horizon; zenital view; underwater landscapes; visual arts and literature

RESUMEN: Aquí estamos interesados en una forma de ver el paisaje de una manera diferente a la habitual y a la que a menudo lo reducimos. En lugar de horizontalmente, a través de un marco y desde un punto de vista, la idea es considerarlo verticalmente, desde arriba o desde abajo, mostrando que estas formas de verlo son de alguna manera potentes en nuestra comprensión de cualquier paisaje. Este texto explora estos potenciales a través del arte y la literatura.

PALABRAS CLAVE: gesto; semántica; sinestesia; percepción; lenguaje

Citação recomendada:

TIBERGHIEN, Gilles. A paisagem de ponta-cabeça. Revista Poiésis, Niterói, v. 21, n. 36, p. 15-34, jul./dez. 2020. [https://doi.org/10.22409/poiesis.v21i36.42733]

(cc) BY-NC-ND Este documento é distribuído nos termos da licença Creative Commons Atribuição-NãoComercial 4.0 Internacional (CC-BY-NC) @ 2020 Gilles Tiberghien 


\section{A paisagem de ponta-cabeça}

Associa-se frequentemente o aparecimento da paisagem na pintura ocidental à invenção da perspectiva. Essa tese dever ser, sem dúvida, matizada, mas caracteriza bem a ideia de que a paisagem é uma forma de representação equilibrada cujo modelo seria a abertura, chamada de veduta pelos italianos, visível no fundo de certos quadros do Renascimento, que o filósofo Alain Roger indicou como a marca da invenção da paisagem.

\author{
A janela, ele escreve, é de fato a moldura que, \\ isolando-a, encaixando-a na pintura, institui 0 \\ país como a paisagem. Uma tal subtração - ex- \\ trair o mundo profano da cena sagrada - é na re- \\ alidade uma adição: éa "agem" que se adiciona \\ ao "país"... (ROGER, 1997, p. 20).
}

Essas análises tornaram-se célebres. A janela, na verdade, de acordo com esse autor, permite não apenas a laicização desse pedaço de natureza assim recortado, que 
deixa então de ser essencialmente uma alegoria religiosa que se pode decifrar apenas graças a algumas chaves de leitura, como também um fator de unificação, ou dito de outra forma, de equilíbrio. Assim, em sua definição doravante clássica, "velha, embora surpreendentemente persistente", como constata John Brinkerhoff Jackson, a paisagem é considerada como "uma parte da superfície da terra que se pode abarcar com um único golpe de vista". (JACKSON, 2003, p. 57)

Três traços desde então caracterizam a paisagem: um ponto de vista que reenvia de modo simétrico a um ponto de fuga, um enquadramento no interior do qual ela é percebida e um horizonte, esse "lugar onde a terra e o céu tocam-se" e que, para um paisagista como Michel Corrajoud, condensava e resumia todas suas outras características. O horizonte é um ponto de equilíbrio além e aquém do qual a vista alternase e onde, uma vez seu limite transpassado, não se está mais certo do que se vê. Os aviadores o sabem muito bem porque há muito tempo têm aparelhos que lhes permitem, mesmo tendo sua aeronave virada de ponta cabeça, entender onde estão em relação à terra. Antigamente, clinôme- tros, níveis de líquido, hoje giroscópios, desempenham o papel de horizontes artificiais, para estabilizar o avião.

Por isso, remetemo-nos a essas paisagens não mais percebidas de modo clássico na escala humana, com os pés sobre a terra, mas do alto, além do horizonte real, ou de baixo, aquém desse mesmo horizonte (Fig. 1). Momentos raros reservados a certos "volantes" ou a certos exploradores das profundezas cujas sensações a arte tentou restituir-nos. Isso constitui o conjunto que compõe o que compreendo por "paisagens de ponta-cabeça"2. Efetivamente, o que vemos mais comumente nessas obras são potencialidades, potências atualizadas que não correspondem a nenhuma percepção verdadeira das paisagens, mas que estão contidas em cada uma delas.

As vistas aéreas satisfazem em nós um desejo de abarcar o espaço o mais amplo possível para ultrapassar a linha do horizonte que delimita nosso conhecimento. Ver do alto consiste em empurrar essa linha sempre para mais longe. No entanto, esse prazer paga-se também com um inconveniente proporcional, pois é verdade que, de quanto mais longe eu olho, mais 


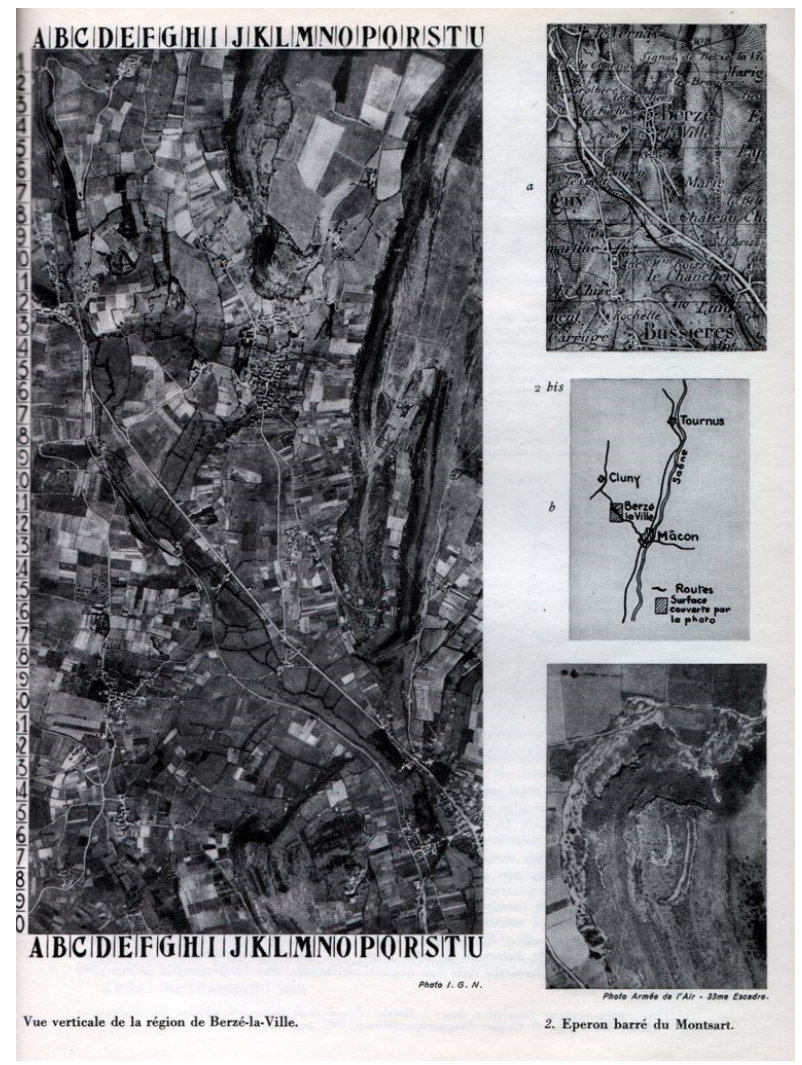

Fig. 1 - La découverte aérienne du monde (ilustrações do livro) Paul Chombart de Lauwe \& Alii

(editado por Horizons de France, 1948)

Revista Poiésis, Niterói, v. 21, n. 36, p. 15-34, jul./dez. 2020. (https://doi.org/10.22409/poiesis.v21i36.42733) 
eu abarco, mas ao mesmo tempo menos detalhes eu vejo, fenômeno próprio às variações de escalas que todos cartógrafos conhecem bem. Além disso, o sentimento de elevação que experimentamos excita em alguns de nós o que Gaston Bachelard, a propósito de Nietzsche, chamara de "psiquismo ascensional", essa necessidade que experimentamos de libertar-nos da gravidade, o que os sonhos de voo puderam testemunhar antes de nossas experiências nesse âmbito (Fig. 2).

Charles Nodier, assim, propôs submeter à Academia Francesa a seguinte questão: "porque o homem que nunca sonhou que ele cruza o espaço sob asas como todas as criaturas voadoras que o envolvem sonha tão frequentemente que se eleva com uma potência elástica, à maneira do aeróstatos, e porque ele sonhou por tanto tempo antes da invenção dos aeróstatos, uma vez que esse sonho é mencionado em todas as onirocríticas antigas, essa previsão não é o sintoma de um de seus progressos orgânicos." (apud BACHELARD, 1990, p. 34). A literatura é efetivamente repleta de narrativas de personagens que voam, a começar pelas Mil e uma noites e seus tapetes voadores em que nos são dadas descrições precisas destas vistas do alto.
E a pintura ofereceu-nos representações de paisagens, como se pode ver em Bruegel ou Altdorfer, por exemplo. no século XVI, bem antes que pudéssemos sobrevoá-las.

Mas, ainda uma vez, não é porque assistimos asas que voamos, mas porque voamos em sonhos é que elas aparecem. As asas são apenas consequências, e o princípio que nos eleva e nos faz voar é mais profundo. (BACHELARD, 1990, p. 37) Trata-se de uma imaginação material que nos anima e nos leva aos ares, e não apenas uma espiritualidade em busca do absoluto. A vista do alto nos dá, ao mesmo tempo, um tal recuo sobre o mundo que nos faz considerá-la como um jogo ou como uma maquete, imagens que voltam frequentemente àqueles que descreveram sua ascensão em um balão como Nadar em seu livro Quando eu era um fotógrafo. Mas sua descrição é também aquela de superfície ornamental que se estende sob nossos pés:

\section{Sob nós, como para nos honrar acompanhando nossa marcha, a terra se desenvolve em um imenso tapete sem bordas, sem começo nem fim, com cores variadas no qual a dominante é 0 ver- de, em todas suas tonalidades como em todas suas fusões. (NADAR, 1994, p. 97)}




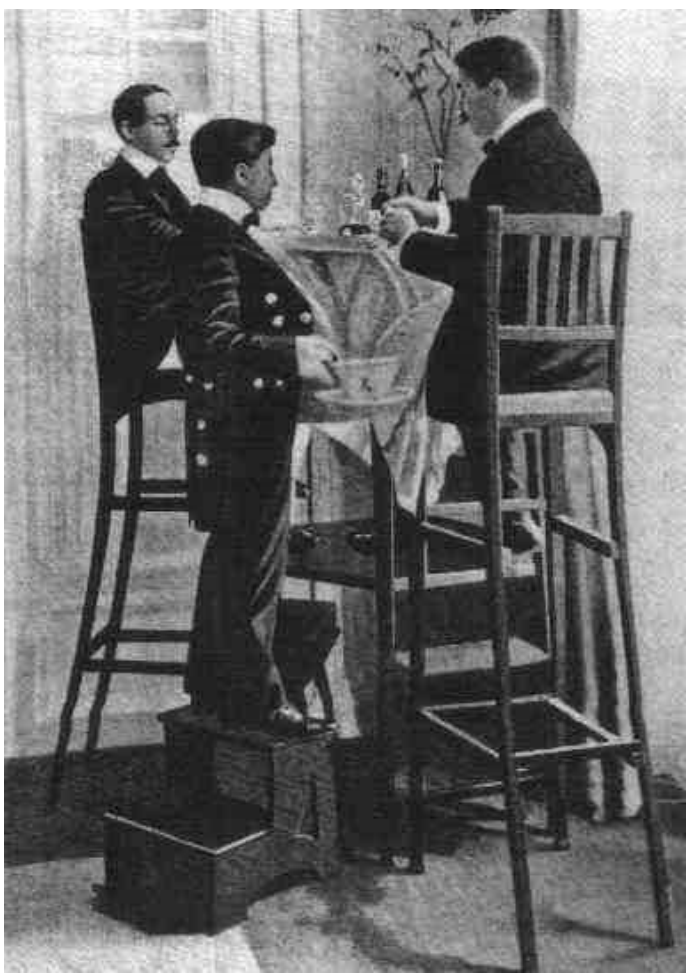

Fig. 2 - Mesa aérea de jantar na residência de Santos Dumont (Fonte: http://theappendix.net/issues/2014/4/the-aviators-heart) 
Será assim em todas as narrativas de experiência em balão: a paisagem desfila sob seus olhos ao mesmo tempo em que eles sentem que flutuam sem mais nenhum anteparo. Eles sentem que flutuam em um tipo de embriaguez suave nos limites da vertigem. Santos Dumont, que realizou o primeiro voo de avião na Europa em 1907, escreveu em sua autobiografia, No ar, que durante sua primeira viagem a bordo de um balão:

\section{[...] a terra, em lugar de parecer redonda como uma bola, apresentava a forma côncava de uma tigela, por efeito do fenômeno de refração que faz o círculo do horizonte elevar-se continuamen- te aos olhos do aeronauta. [...] As pessoas apre- sentavam 0 aspecto de formigas caminhando so- bre linhas brancas, as estradas; as filas de casas assemelhavam-se a brinquedos de crianças. (SANTOS DUMONT, 2016, p. 40)}

Essa experiência será artisticamente prolongada pelos futuristas italianos, mas de uma maneira dinâmica. A multiplicação de pontos de fuga, a sobreposição dos espaços, os efeitos de desenquadrar foram cultivados pelos adeptos da aeropintura, cujo manifesto foi publicado em 1929. Lê-se ali em particular que as perspectivas cambi- antes do voo abrem uma nova realidade, cujos elementos "não têm nenhuma base firme e são construídos pela própria mobilidade perpétua, e o pintor somente pode não pode observá-la e reproduzi-la na medida em que participa desta mesma mobilidade." (LISTA, 1973, p. 369) 3

Em seguida, virão a aeropoesia, a aeromúsica, com Russolo, por exemplo, ou a aerofotografia de Masoero ou de Fedele. 0 Vorticism inglês cultivará esses movimentos de turbilhões e de espiral que Robert Smithson, leitor de Ezra Pound e Wyndham, lembrará ao intitular uma de suas obras de 1965 de Four Sided Vortex, misturando as referências aos futuristas ingleses com a cristalografia. No mesmo espírito e a propósito do projeto de filmagem de Spiral Jetty, ele escreverá: "Para meu filme (o filme é uma espiral feita com imagens sucessivas), me deixarei filmar de um helicóptero (do grego helix, helokos, que significa espiral) diretamente acima da minha cabeça a fim de ter a escala da irregularidade dos meus passos." (SMITHSON, 1994, p. 207)

Em $A$ descoberta aérea do mundo, obra dirigida por P. Chomabart de Lauwe e pu- 
blicada em 1948, Pierre Marthelot escrevia que "apenas a visão aérea vertical permite ver as coisas face-a-face". Entretanto, essa vista frontal, ele acrescenta, achata o relevo e "destaca-nos a superfície das coisas" (DE LAUWE, 1948), colocando tudo o que vemos sobre um mesmo plano por um efeito ótico de equalização que nos fecha na "forma quadro" (Fig. 1). Isso lembra o que Gertrud Stein escrevia em seu livro sobre Picasso:

\section{Quando estava na América, fiz pela primeira vez viagens contínuas de avião. Vi misturadas sobre a terra as linhas de Picasso indo e vindo, desenvol- vendo-se e destruindo-se; vi as soluções simplifi- cadas de Braque, a linha errante de Masson. Sim, vi tudo isso e mais uma vez compreendi que um criador é sempre um contemporâneo. Antes de todo mundo, ele conhece o que os outros ainda não sabem. Ele está no século $X X$, um século que vêa terra como nunca a vimos, que tem um es- plendor jamais igualado. Tudo se destrói, nada permanece. (STEIN, 1978, p. 91 apud ASENDORF, 2013, p. 265)}

Os pintores não deixaram de ser impressionados por esses gêneros de vistas, como Richard Diebenkorn que, no início dos anos 1950, começara sua série Ocean Park. Nos anos 1960, todos os artistas estadunidenses possuíam no espírito as obras de Pollock, seus famosos drippings, realizados sobre as telas na horizontal, e as fotografias, como o filme de Namuth, que os popularizaram. Se, para essa geração, o expressionismo abstrato foi uma referência positiva, ele também foi objeto de rejeição. No entanto, essa perspectiva zenital, assim colocada em evidência, transformou o olhar desta mesma geração sobre a arte.

Ora, justamente o artista Robert Morris, tocado como muitos outros de sua geração pela redescoberta dos trabalhos de Maria Reiche sobre Nazca, irá ao Peru em 1975 para andar sobre as linhas que ela estudou, mas sem ter recorrido previamente à vista aérea. Dessa experiência, ele retirará um texto publicado na Artforum em novembro de 1976 -Aligned with Nazca - em que ele se interessa por um par conceitual "o plano" (espaço neutro e simbólico) e o "espacial" (espaço para o sujeito que faz concretamente a experiência do mundo). Essa oposição lembra aquela descrita por Erwin Strauss entre o espaço geográfico - que conhecemos particularmente graças aos mapas - e o espaço paisagístico que experimentamos fi- 
sicamente. Ora, é nessa experiência real do "espacial" que Morris compreende então a continuidade entre o " $\mathrm{si}$ ", o self, e o mundo, entre o sujeito e o objeto. O plano é o lugar de nossas notações, ele é o plano da escrita. "Utilizamos os sistemas de notação, adotando a distância que os torna inteligíveis: eles são extraespaciais." (MORRIS, 1975)

O que vemos do céu é comparável a um sistema de notações. A notação que se refere à superfície nos permite dominar o tempo e o espaço, mas exclui o mundo sensível. No mundo das superfícies planas, a notação é a rainha. O controle é total. Trata-se, como foi dito, do mundo do mapa. Mas o mundo em três dimensões não é nada seguro e a errância é sempre possível. Morris, então considera Nazca de duas maneiras:

Estamos prontos a incluir, em nossa visão do traçado de Nazca, a totalidade da paisagem. Devemos levar em conta não apenas as linhas, mas as montanhas. Supondo que as primeiras indicam tanto fontes de água bem reais quanto pontos de força espirituais localizados na serra, estamos então na presença dos seguintes pares dialéticos: 0 plano e o espacial, a linha e a montanha, a figura e 0 objeto, a abstração e a realidade. Aqui, o símbolo-artefato opera de modo a orientar, na direção de um projeto humano, as forças da natureza. Essas circulam ao longo dos traços deixados pelo artista, cujo símbolo linear age como um condutor de uma energia espiritual que refluiria em sua direção ao longo das linhas. (MORRIS,

1975)

Para os artistas da land art, a vista do céu foi um instrumento para documentar suas obras, mas também para fabricá-las. O exemplo de Robert Smithson é eloquente desse ponto de vista. Em junho de 1966, respondendo ao convite do arquiteto Walther Prokosch, que trabalhava para o escritório de arquitetura Tibbets, Abbott, McCarthy e Stratton (TAMS), ele tornou-se consultor para o projeto de construção do aeroporto regional de Dallas. Por um ano e meio, ele refletiu sobre o que poderia ser uma "arte aérea" tal como, dispostos nas margens do aeroporto, os earthworks que veríamos do céu.

Sua própria contribuição consistia na construção de um grande mapa aéreo (Aerial Map), uma grande espiral plana, que antecipava seu Spiral Jetty, formada de elementos geométricos e visível do 
céu. Sem entrar no detalhe desse projeto, lembremos que, para Smithson, o que estava em jogo não era tão somente a percepção do espaço, mas igualmente nossa consciência do tempo.

Essas transformações da percepção do espaço e do tempo correspondem também à nossa relação com o mundo modificado pelas tecnologias da comunicação que desmaterializam o corpo e oferecem-lhe, ao mesmo tempo, próteses óticas e táteis que o prolongam até zonas insuspeitas. Fato que, evidentemente, interessava vivamente aos artistas.

Mas a perspectiva contrária não é exclusiva apenas dos ases da aviação, aficionados de loopings. Ela é também aquela de quem se aventura a olhar sob o horizonte. Desde a antiguidade, pensou-se que a face visível da Terra escondia um mundo subterrâneo ao qual poder-se-ia acessar por portas secretas onde se situavam as moradias infernais. Pôde-se mesmo falar de uma "geografia dos infernos" na Odisséia ou na Eneida, com suas gargantas obscuras, seus rios de fogo, seus caminhos levando ao Aqueronte. Para os gregos e latinos, era pelo covil de Cumes, onde a Sibila profetizava, que se podia penetrar ali.

Pudemos pensar que cidades, até países inteiros, estendiam sob nossos pés um segredo conhecido por alguns, mas que a maior parte das pessoas nem ao menos suspeitaria. As especulações mais fantasiosas tentaram dar consistência a algumas narrativas sem nenhum fundamento, mesmo se, nesse âmbito, alguns cientistas procurassem sustentar o que chamamos de "teoria da Terra oca".

Essa teoria foi formulada na Renascença pelo padre jesuíta Anathasius Kircher em seu Mundus subteranneus (1665), no qual ele indica a localização da Atlântida e as nascentes do Nilo. Mas, sobretudo, ele afirma que o interior da terra é oco com múltiplas cavidades onde circulam a água e o fogo (Fig. 3). Kircher, aliás, compara a circulação subterrânea das águas àquela do sangue no corpo humano, tal como descrito pelo médico contemporâneo de Descartes, William Harvey. Outras teorias militam a favor de tais mundo subterrâneos. 


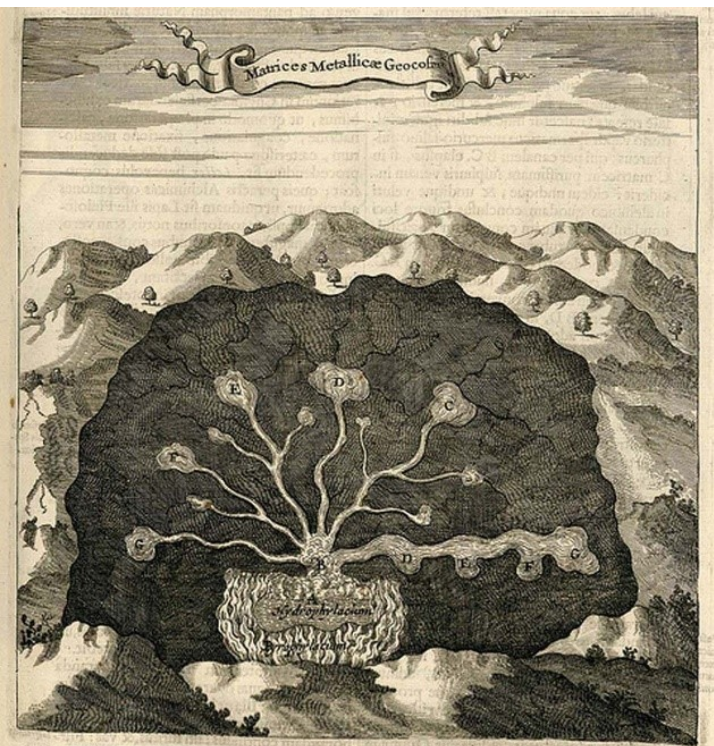

Fig. 3 - Athanasius Kircher, Mundus Subterraneus

(Fonte: https://michelkoven.files.wordpress.com/2012/06/mundus-subterraneus-ii.jpg)

Gilles Tiberghien, A paisagem de ponta-cabeça. 
O século XIX deu um prolongamento romanesco a essas especulações ao imaginar expedições nas profundezas que antecipam o célebre romance de Jules Verne Viagem ao centro da Terra, publicado em $1864 .{ }^{4}$ No romance de Jules Verne, a expedição que ele imagina penetra sempre mais profundamente na terra para acessar pouco a pouco o "terreno primitivo" (Fig. 4). Ali, diz o narrador, "a luz dos apareIhos, repercutida pelas pequenas facetas da massa rochosa, cruzando seus jatos de fogo sob todos os ângulos, e eu me imaginava viajando através de um diamante oco no qual os raios quebravam-se em mil brilhos". (VERNE, 1867, p. 108-109) Reencontra-se aqui algo desses devaneios cristalinos caros aos Românticos alemães e a esse imaginário dos mineiros, sublimado pelos poetas da época. Assim, em Henri d'Ofterdingen, Novalis - que tinha uma formação de geólogo e participara ativamente na inspeção das Salinas de Dürrenberg, Kösen e Arten, dirigidas por seu pai - conta como Henri, acompanhado de um mineiro, vai explorar uma grota onde ele encontra um eremita, um nobre desde então retirado do mundo, que declara ao mineiro: "Você é um pouco um astrólogo às avessas", acrescentando para explicitar essa imagem: "enquanto esses guardam os olhos fixos ao céu e exploram seus espaços infinitos, você volta seus olhares para a terra e sonda sua estrutura". (NOVALIS, 1976, p. 143) Daí a oposição entre essa disciplina capaz de ler o céu como "o livro do futuro" e a geologia, para a qual "as figuras da Terra revelam as origens do mundo."

Essas origens, naturalmente, são mais fantasmáticas do que reais. Todos os "romances subterrâneos" tratam disso. Mas elas são o fruto de uma construção, o que traduz bem à sua maneira Grotto (2006), obra de Thomas Demand realizada em papelão e modelizada inteiramente em um computador (Fig. 5). Seja como for, o subsolo é o lugar do segredo, até do mistério, também da fuga. Foge-se das coisas que se quer dissimular do mundo e, às vezes, de nós mesmos. No Fantasma da Ópera, de Gaston Leroux, um ser com o rosto desfigurado esconde-se e assombra os subsolos do edifício, construído, diz-se, sobre um lago artificial concebido pelo arquiteto Charles Garnier. No romance, o lago é alimentado por um rio e nesse subsolo encontra-se o indício do "fantasma". 


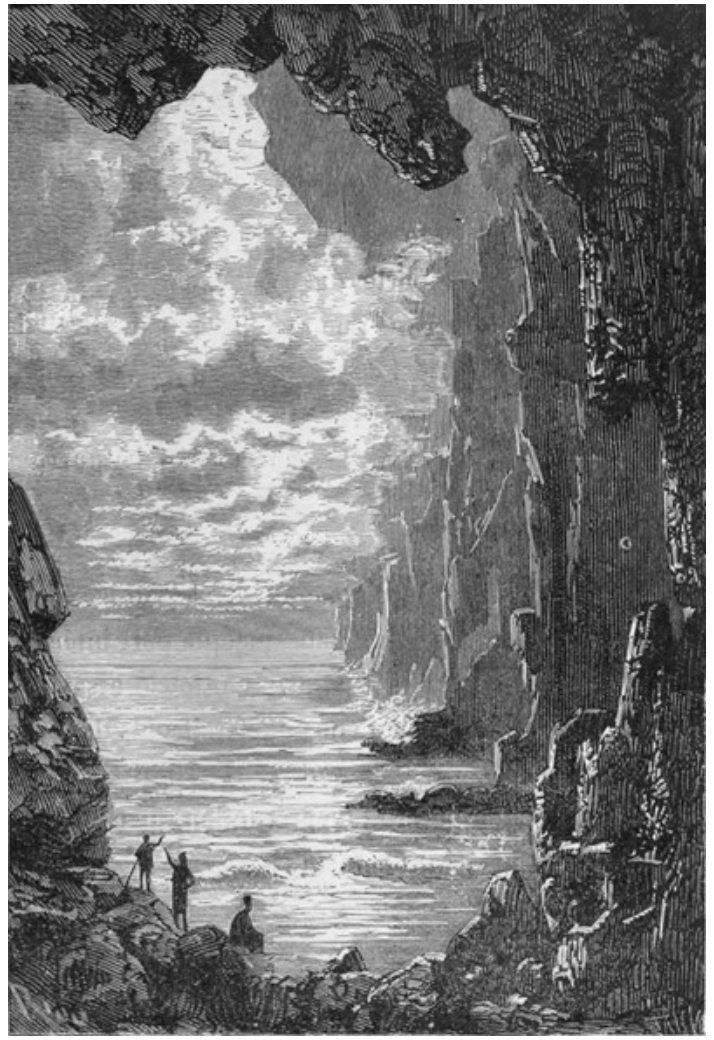

Fig. 4 - Jules Verne, Voyage au centre de la Terre (1864).

Ilustrações originais de Edouard Riou

(Fonte: http://jv.gilead.org.il/rpaul/Voyage au centre de la terre/) 
Edgar Rice Burroughs, o famoso autor de Tarzan, retomando o mito da Terra oca, imagina nos anos 1930, com o ciclo Pellicidar, seus personagens que exploram um mundo subterrâneo cuja geografia tem essa particularidade de não apresentar nenhum horizonte verdadeiro em razão de sua natureza côncava:

\section{Eu levantei os olhos e comecei a supor a razão dessa estranha paisagem que me tocara desde o início por seu caráter insólito e pouco conforme ao natural: não havia horizonte! Tão longe quanto o olho podia alcançar, o mar estendia indefinidamente sua super- fície salpicada de ilhas minúsculas, as mais afastadas reduzidas ao estado de simples pontos; mas, além, era sempre 0 oceano e quando se procurava desco- brir 0 seu limite, era preciso elevar 0 olhar a fim de descobrir o ponto mais afastado perceptível para a visão. (BURROUGHS, 1971, p. 32)}

Sem horizonte, o que é uma paisagem, se é que se faz ainda sentido empregar essa palavra para descrever o que se oferece à vista do intrépido explorador?

Entretanto, em Jules Verne, quando nossos aventureiros chegam à margem do que parece ser um oceano que se estende sob um tipo de imenso globo, o narrador observa:
Nós estávamos realmente aprisionados em uma enorme escavação. Não era possível julgar nem sua largura, uma vez que o rio se alargava a perder de vista, nem seu comprimento, pois o olhar era logo parado pelo uma linha do horizonte um pouco indecisa. (VERNE, 1867)

Esse horizonte é sempre incerto: sua linha não é nítida e o narrador explica que escrutinando ao longe, ele procurava "rasgar essa cortina lançada no fundo misteriosos do horizonte". (VERNE, 1867)

Que ele vacile, que seja sem nitidez, indeciso, isso não significa que nós não lidemos com uma paisagem. Pode-se pensar, como Erwin Strauss, que o horizonte se apresenta não como um limite, mas como um convite a sempre ultrapassá-lo, pois o homem "não pode mais parar inteiramente na paisagem a não ser que ele possa escapar dali completamente". (STRAUSS, 1989, p. 527) O horizonte desloca-se sempre conosco e, nas profundezas da Terra, isso não é nada que possamos verdadeiramente identificar, pois ele reflui ou imobiliza-se e suas transformações não dependem apenas da nossa visão, mas são ligadas ao movimento do nosso corpo inteiro, não apenas em relação aos seus 


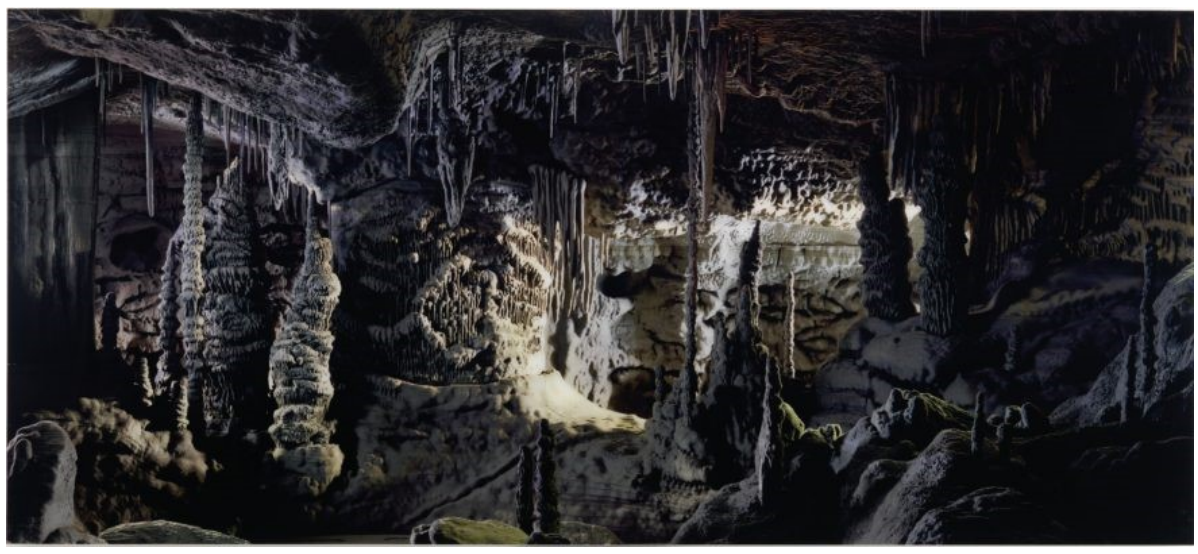

Fig. 5 - Thomas Demand, Grotto, 2006. (maquete modelizada em papelão) Installation image courtesy Pier 24 Photography

(Fonte: https://www.thedailybeast.com/thomas-demand-at-pier-24-is-the-daily-picby-blake-gopnik) 
avanços no espaço, mas às suas sensações, olfativas, auditivas, táteis etc.

A arte do século $X X$ interessou-se muito cedo por essas paisagens de baixo e pelas modificações que elas supõem em nós, em artistas como Jean Painlevé, suposto documentarista, mas que revela de fato um mundo na interseção do que ele de fato via e do que imaginava. Próximo aos surrealistas - ele contribuía com a revista de Bataille Documents em 1929 -, Painlevé publica suas fotografias em um número considerável de revistas nos anos 1930, na França, mas também na Itália e na Argentina. Jean Cassou, em um texto de 1931, intitulado "a arte submarina", escreverá que a

\section{arte decorativa, a arte dramática dos animais submarinos convém a nosso olho, a nosso gosto, a nosso ritmo. Na sua contemplação, encontra- mos 0 mesmo prazer emotivo e a mesma satisfa- ção intelectual que marca para nós tudo o que é do nosso planeta. (CASSOU, 1931)}

Ali ainda alguma coisa dos movimentos internos de nosso corpo antecipa realidades que podemos ver. Essa é a virtude da arte de oferecer-nos imagens dessas realida- des invisíveis que são ao mesmo tempo o reverso de nossas paisagens vistas e experimentadas.

Em 1969, uma pequena exposição, $A R e-$ port: Two Ocean Projects, reuniu no $\mathrm{Mu}-$ seu de Arte Moderna de Nova York, Peter Hutchinson e Dennis Oppenheim. As obras de Peter Hutchinson são apresentadas sob a forma de montagens constituídas, o mais frequentemente, por uma grande imagem sob a qual, à maneira de uma predela, são dispostos tanto a mesma imagem diminuída quanto detalhes da instalação, com um mapa da ilha de acordo com o caso. O artista enganchou cabaças ao longo de uma corda de $350 \mathrm{~cm}$, flutuando livremente sobre a água, decompondo-se pouco a pouco, já que se trata de frutas frescas e não de cascas, contrariamente ao que sugere o título Threaded Calabash. Ele também plantou flores em triângulo e formou uma pequena barragem inútil no fundo do mar, criando estranhas paisagens submarinas que falam de um mundo que pertence ao universo da ficção científica, em que se pode ver brotar flores em um meio que não é o seu. 
Trata-se de nosso mundo, mas de um ponto de vista novo, aquele de uma criatura marinha, por exemplo. Esse "devir animal", para falar como Gilles Deleuze, encontra-se também no artista francês Marcel Dinahet. A arte, para ele, é um modo de pressentir a descrição de mundos possíveis, de imaginá-los com um apareIho ótico, uma lente fotográfica ou uma câmera, capaz de traduzir o que nosso olho poderia ver se fossemos um peixe, uma lontra ou uma aranha d'água, ou se nós tivéssemos nos tornado anfíbios, perseguindo a metamorfose possível dos hu-

Por seu turno, em Going Nowhere (2011), o artista Simon Faithfull anda com certa dificuldade no fundo do mar Adriático, em uma paisagem rochosa, de algas e peixes, em camisa e calça negra. Ele avança como nesses sonhos em que temos a impressão de sermos perseguidos por alguma coisa ou alguém da qual ou de quem temos dificuldade de escapar: nossa humanidade, talvez? Outros artistas tentam dar a ilusão de uma dependência perfeita com um meio que não é o seu, como Philippe Ramette que se deixa fotografar de terno, orientando-se com um mapa em uma paisagem submarina.

Esses modos de olhar a paisagem descentram-nos, de alguma maneira, da terra, que é o nosso primeiro solo, e de nós mesmos, abandonados desse solo e agarrados por outros movimentos que nos metamorfoseiam e fazem de nossas paisagens meios sem indicações. O modo como apreendemos o tempo é provavelmente para nós um modo de sintetizar e de hierarquizar todos nossos outros sentidos para submetê-los aos imperativos práticos que a visão comanda. Mas, sob a terra ou sob a água, mesmo se não vemos ou vemos pouco, o corpo torna-se um sensor sinestésico e, o mundo, ao inverso de nosso psiquismo que parece dilatar-se, comprime-se ou dilui-se progressivamente. Mais o espaço restringe-se, mais as paisagens subterrâneas ou submarinas tornam-se os reinos de uma imaginação espalhada e suspensa. O tempo então adormece em nós e muitos espeleólogos ou mergulhadores contam quanto o sentimento da duração é diferente sob a terra ou sob o mar, como se tudo fosse retardado. Permanecem as estrelas no céu ou no fundo das águas para guiar-nos ou para perder-nos nessas paisagens doravante de ponta-cabeça. 


\section{Notas}

${ }^{1}$ Gilles A. Tiberghien é professor de Estética na Université Paris 1 - Panthéon-Sorbonne. Ensina também na l'École Nationale du Paysage de Versailles, assim como no Institut d'Architecture de Genève. É membro do comitê de redação dos Cahiers du Musée d'Art Moderne et des Carnets Du Paysage e dirigiu a coleção arts et esthétique da Editora Carré, Hoëbeke et Desclée de Brouwer. É autor de diversas obras dedicadas à arte e paisagem, dentre as quais Land Art (Éditions Carré, 1993), Nature, art, paysage (Actes Sud/École Nationale Supérieure du Paysage, 2001) et Notes sur la nature, la cabane et quelques autres choses (Éditions Le Félin, 2005). Escreveu também sobre outros temas, como Marcel Proust, Les vrais paradis, sont les paradis qu'on a perdus (Éditions de la Martinière, 2004) e sobre o sentimento amoroso Aimer, une histoire sans fin (Éditions Flammarion, 2013).

${ }^{2}$ Gilles Tiberghien criou essa fórmula "Le paysage sens dessus dessous" a partir da expressão francesa "sens dessus dessous", que significa aproximadamente o mesmo que a expressão em português "de pontacabeça", tanto no sentido de que indica a inversão de posição entre o que está no alto e o que está embaixo, quanto no sentido da geração de uma grande confusão por causa de uma mudança brusca, como quando se diz que "minha vida está de ponta-cabeça". No entanto, é preciso notar que o autor também se vale do sentido literal da expressão francesa "sens dessus dessous", cuja tradução seria "sentido de cima abaixo". Jogando com os sentidos da expressão, o autor quer indicar uma transformação no modo de percepção da paisagem, construída no Renascimento, a partir de uma vista horizontal. Tal transformação consistiu justamente em considerar a paisagem verticalmente, mudando a percepção horizontal na medida em que ela poderia ser contemplada de cima ou de baixo.
${ }^{3} \mathrm{O}$ texto é assinado por Marinetti, Balla, Cappa, Dottori, Fillia, Prampolini, Somenzi Despero et Tato, cf. LISTA, 1973, p. 369. Ver também ASENDORF, 2013, p. 47-58.

${ }^{4} \mathrm{O}$ livro foi publicado em 1867 com dois capítulos a mais.

\section{Referências}

ASENDORF, Christoph. Super Constellation. Trad. Didier Renault et Augustine
BACHELARD, Gaston, L'air et les songes. Paris: José Corti, 1990.

BURROUGHS, Edgar Rice. Pellucidar. Au cœur de la Terre. Trad. Pierre Billon. Paris: Opta, 1971.

CASSOU, Jean. L'Art sous-marin. Art et Décoration, n. 59, p. 143-150, jan./jun. 1931.

JACKSON, J. B. A la découverte du paysage vernaculaire. Arles: Actes sud/ENSP, 2003.

LAUWE, P. Chombart. La découverte aérienne du monde. Paris: Horizons de France, 1948. 
LISTA, Giovanni. Futurisme, Manifestes, documents, proclamations. Paris: L'Age d'Homme, 1973.

MORRIS, Robert. Aligned with Nazca. Artforum, oct. 1975, p. 26-39.

NADAR, Félix. Quand j'étais photographe. Paris: Le Seuil, 1994.

NOVALIS. Henri d'Hofterdingen. Trad. Robert Rovini. Paris: UGE, 1967.

ROGER, Alain. Art et anticipation. Paris: Carré, Arts et Esthétique, 1997.

SANTOS DUMONT, Alberto. Os meus balões (dans l'air). Trad. A. Miranda dos
Santos. Brasília: Edições do Senado Federal, 2016.

SMITHSON, Robert. Une rétrospective, Le paysage entropique, 1960-1973. Trad. Claude Gintz. Marseille: M.A.C., 1994.

STEIN, Gertrud. Picasso. Paris: Christian Bourgois, 1978.

STRAUSS, Erwin. Du sens des sens. Grenoble: Jérôme Million. 1989.

VERNE, Jules. Voyage au centre de la Terre. Paris: Hachette, 1867. 